\title{
Placental Transfer of Glucose and Amino Acids in Intrauterine Growth Retardation: Studies with Substrate Analogs in the Awake Guinea Pig
}

\author{
THOMAS JANSSON AND ELISABET PERSSON \\ Department of Physiology, Division of Perinatal Physiology, and Department of Pediatrics I, University of \\ Göteborg, Göteborg, Sweden
}

\begin{abstract}
After experimentally inducing growth retardation by unilateral uterine artery ligation in midpregnancy, placental blood flow (PBF) (microsphere technique) and placental transfer of ${ }^{14} \mathrm{C}$-aminoisobutyric acid (AIB) and ${ }^{3} \mathrm{H}$-methylglucose (MG) were studied at $\mathrm{d} 44,50$, or 63 of gestation in 19 chronically catheterized awake guinea pigs. At d 44, fetal wt (FW) and placental wt were reduced by 16 and $18 \%$, respectively, in the ligated horn and FW/ PBF was increased by $122 \%$. Placental efficiency to transfer MG and AIB (fetal dpm/g placenta) was maintained in the ligated horn, feto-placental extraction (feto-placental $\mathrm{dpm} / \mathrm{PBF}$ ) was increased, and placental transfer of the substrate analogs (fetal dpm/g fetus) was unchanged. At d 50 and 63, placental wt and $\mathrm{FW}$ were reduced in proportion $(\sim 40 \%)$ in the growth-retarded group and FW/PBF was increased by 80 and $51 \%$, respectively. Placental transfer of AIB was reduced by $33 \%$ at $d 50$ and by $18 \%$ at $d 63$. In addition, placental efficiency to transfer AIB was reduced by $36 \%$ at $\mathrm{d} 50$ and by $22 \%$ at $\mathrm{d} 63$ in the growthretarded group. Fetal uptake of MG per $\mathrm{g}$ fetus was slightly reduced $(-6 \%)$ at d 50 of gestation, but unaffected at $d 63$. Extraction of MG from the maternal PBF was increased, whereas the wt-specific transfer capacity of the placenta was unaltered. Our results demonstrate that experimental growth retardation in the guinea pig is associated with a substantial reduction of $\mathbf{F W}$-specific placental transfer of AIB, indicating that the growth-retarded fetus has an impaired supply of amino acids during intrauterine life. This reduction is suggested to be due to alterations at the placental barrier level and will contribute to the development of intrauterine growth retardation independently of the PBF decrease per se. Placental transfer of MG per $g$ fetus was only moderately reduced at $\mathbf{d} 50$ of gestation, but otherwise maintained. Consequently, compromised placental glucose transfer is not likely to be the main cause of fetal hypoglycemia in guinea pig intrauterine growth retardation. (Pediatr Res 28: 203-208, 1990)
\end{abstract}

\section{Abbreviations}

AIB, ${ }^{14} \mathrm{C}$-aminoisobutyric acid

MG, ${ }^{3} \mathrm{H}$-methylglucose

FW, fetal weight

PBF, placental blood flow $(\mathrm{mL} / \mathrm{min})$

Received December 12, 1989; accepted March 24, 1990

Correspondence and reprint requests: Thomas Jansson, M.D., Division of Perinatal Physiology, Department of Physiology, University of Göteborg, P. O. Box 33031. S-400 33 Göteborg, Sweden.

Supported by grants from Expressen Prenatal Research Foundation, General Maternity Hospital Foundation, Magnus Bergvall Foundation, Swedish Research Council (no. 2591), Faculty of Medicine, University of Göteborg, Göteborg Medical Society, the "Samariten" Foundation, Swedish Society for Medical Research, and Sahlgren's Hospital Foundation.
IUGR, intrauterine growth retardation $\mathrm{PE}$, polyethylene

Reduced placental transfer of nutrients due to impaired maternal PBF and/or placental dysfunction is implicated as one of the causative factors of IUGR. Varying degrees of fetal hypoglycemia are consistently found in most experimental models of IUGR, such as the fetal sheep (1) and guinea pig (2), and have also been demonstrated in the undisturbed human fetus (3). The umbilical vein-artery concentration difference of $\alpha$-amino nitrogen, measured by cord blood sampling after delivery, is reduced in small-for-gestational-age infants (4), a finding that has been confirmed recently by transabdominal cord sampling (5).

Reductions in umbilical plasma concentrations of glucose and amino acids do not, however, provide direct evidence for impaired placental transport of these substrates, inasmuch as other factors besides materno-fetal transfer, such as fetal consumption, may influence fetal plasma levels. An approach to circumvent this problem is to measure placental and umbilical blood flows, as well as extraction, which has been done in the experimentally growth-retarded fetal lamb (1). A method that focuses more directly on placental transfer is the use of radioactively labeled substrate analogs. When placental transfer of glucose was investigated with such techniques in the fetal sheep (6), data suggested that it was enhanced in IUGR. On the other hand, in the anesthetized rat with growth retardation induced by uterine artery ligation, a reduced transfer of both methylglucose and aminoisobutyric acid was demonstrated (7).

Substrate transfer capacity of the growth-retarded hemochorial placenta has only been investigated in anesthetized and acutely instrumented animals $(7,8)$. Anesthesia is known to markedly reduce $\mathrm{PBF}$ and may also, together with the acute surgical stress, influence placental transport characteristics. Therefore, the main objective of our investigation was to study placental transfer of AIB and $M G$ in the unstressed guinea pig after experimental induction of fetal growth retardation by unilateral uterine artery ligation in midpregnancy. It is reasonable to assume that if changes in placental substrate transfer have a major impact on fetal growth, they should not only be demonstrable near term, but also during a substantial part of the gestation. For this reason, and to describe possible changes in placental transfer capacity or compensation mechanisms during the development of growth retardation, experiments were performed at three stages of gestation.

\section{MATERIALS AND METHODS}

The investigations described in this paper have been approved by the local ethical committee for animal experimentation (56/ 89). 
Nineteen nulliparous albino guinea pig does of the DunkinHartley strain were used. The animals were allowed free access to food [standard pellets (Ewos, Södertälje, Sweden) and hay] and water (with ascorbic acid, vitamin $\mathrm{E}$, and selenium added). The animals were maintained in an environment of controlled humidity $(40$ to $70 \%)$ and temperature $\left(18\right.$ to $\left.20^{\circ} \mathrm{C}\right)$ with a 12 -h light-darkness cycle. The day of mating ( $\mathrm{d} 0)$ was determined by daily inspection of the vaginal membrane. Initially, two females and one male guinea pig were housed together, but after pregnancy was confirmed by palpation of the fetuses at $d 15$ to 20 of gestation, the does were transferred to a special room in the animal stables and kept alone in separate cages. From d 20 until the day of experimentation, animals were fed 0.2 to $0.3 \mathrm{~mL}$ of water daily from a syringe to accustom them to handling.

At 31 to 38 (mean $34.8 \pm 0.4$ ) d gestation, the animals were anesthetized with $3-4 \%$ enflurane together with nitrous oxide/ oxygen (1:1). Under aseptic conditions and temperature control (rectal temperature $37.5-38.5^{\circ} \mathrm{C}$ ), a $2-$ to $3-\mathrm{cm}$ lower abdominal midline incision was made. The mesometrial fat pad of one of the uterine horns was exposed and the uterine artery ligated. The operation lasted $10-15 \mathrm{~min}$, and the animals were standing up in their cages within $10 \mathrm{~min}$.

At 38 to 40,42 to 45 , or 49 to $53 \mathrm{~d}$ gestation, animals were anesthetized with ketamine hydrochloride (30 mg s.c.) and $x y-$ lazine ( $3 \mathrm{mg}$ intramuscularly), preceded by atropine $(0.05 \mathrm{mg}$ s.c.). Polyethylene catheters (Becton Dickinson \& Co., Parsippany, $\mathrm{NJ}$ ) were inserted into the femoral artery and advanced to the aortic bifurcation (PE 25, inner diameter $0.40 \mathrm{~mm}$, connected to PE 90 , inner diameter $0.86 \mathrm{~mm}$ ), into the left ventricle by cannulation of the right common carotid artery in the retrograde direction (PE 50, inner diameter 0.58 connected to PE 90), and into the right external jugular vein (PE 50 connected to PE 90). The catheters were tunneled s.c. and exteriorized between the scapulae. A small amount of antibiotic paste (Socatyl vet, CibaGeigy, Basel, Switzerland) was applied to the wounds before closure. The operation lasted 30-60 min. During the operation and postoperatively, the animals were given a total volume of 30 $\mathrm{mL}$ of physiologic saline i.v. over $2^{1 / 2} \mathrm{~h}$. Isoprenaline was added to the fluid at an infusion rate of $1.5 \mu \mathrm{g} / \mathrm{kg} \times \min$ to preserve cardiac output during anesthesia. Glucose was given $(10 \mathrm{mg} / \mathrm{kg}$ $\times$ min) in the last $20 \mathrm{~mL}$. Catheters were filled with heparinized saline solution and sealed. The animals recovered within $3-5 \mathrm{~h}$ after the operation. To maintain patency, the catheters were flushed with heparinized saline every $24 \mathrm{~h}$.

At 44 to 45,50 , or 63 to $64 \mathrm{~d}$ gestation, experiments were performed in the animal room with the animal freely moving in its own cage without any visual contact with the experimenter. After connecting the animal to a swivel, it was allowed $1-2 \mathrm{~h}$ to accommodate to the experimental situation. Throughout the experiment, arterial blood pressure and heart rate were measured by means of a pressure transducer (P23 ID Statham Gould, Hato Rey, Puerto Rico) and an oscillation detector, respectively. All recordings were made on a Grass Instrument (Quincy, MA) polygraph no. 7 .

At time $0, \alpha\left[1-{ }^{14} \mathrm{C}\right]$-aminoisobutyric acid $(10 \mu \mathrm{Ci} / \mathrm{kg})$ and $3-0-$ [methyl- ${ }^{3} \mathrm{H}$ ]-D-glucose $(100 \mu \mathrm{Ci} / \mathrm{kg})$ were given i.v. over $4 \mathrm{~min}$. Substrate analogs were purchased from Du Pont (D-6072 Dreieich, West Germany) and the original solvents were ethanol:water [9:1 (MG)] and 0.01 $\mathrm{N}$ hydrochloric acid solution (AIB), respectively. To $0.1 \mathrm{~mL}$ of the original solutions, $0.4 \mathrm{~mL}$ of saline was added before injection. At $20 \mathrm{~min}$, PBF was measured by means of the microsphere technique. Microspheres with a mean $( \pm \mathrm{SD})$ diameter of $16.5 \pm 0.1 \mu \mathrm{m}$ and labeled with either ${ }^{95} \mathrm{Ni},{ }^{103} \mathrm{Ru}$, or ${ }^{141} \mathrm{Ce}$ (Du Pont, D-6072 Dreieich, West Germany) were used. The microspheres were suspended in saline solution with Tween 80 added. After vigorous vibration with a whirl mixer, 0.6-0.7 mL (corresponding to 400 000-600 000 spheres) were injected into the left ventricle catheter over $45 \mathrm{~s}$, followed by flushing of the catheter with $1 \mathrm{~mL}$ of saline solution over $45 \mathrm{~s}$. A reference blood sample was drawn from the abdom- inal aorta at a rate of $0.65 \mathrm{~mL} / \mathrm{min}$ from $10 \mathrm{~s}$ before the start of the microsphere injection until $75 \mathrm{~s}$ after the end of flushing.

At $25 \mathrm{~min}$ into the experimental period, $1 \mathrm{~mL}$ of blood was sampled from the femoral catheter and the animal was killed by an overdose of barbiturate. After laparotomy, fetuses were promptly dissected out and decapitated to obtain blood samples. Catheter positions were checked and all were found to be adequate. After weighing, placentas and kidneys were partitioned and placed into counting vials. The radioactivity of the samples was determined in a multichannel pulse height analyzer (Packard 5019 connected to Packard 3220; Packard Instrument Co., Inc., Downers Grove, IL). Organ blood flows were calculated by the following formula: Organ blood flow $(\mathrm{mL} / \mathrm{min})=($ No. of microspheres in organ $\div$ no. of microspheres in reference blood sample $) \times$ withdrawal rate $(\mathrm{mL} / \mathrm{min})$. No experiment contained less than 580 microspheres in placentas, kidneys, or reference blood sample. The lower blood flow $(\mathrm{mL} / \mathrm{min} \times \mathrm{g})$ of the two kidneys was divided by the higher blood flow value, giving a ratio $\leq 1.0$ for each microsphere injection; the mean ratio was $0.95 \pm 0.01$ (range 0.82 to 0.99 ), indicating an adequate mixing of spheres.

To determine concentrations of substrate analogs, fetuses, placentas (obtained from the gamma radiation counting vials), and blood samples were homogenized in four volumes of distilled water and $20 \%$ trichloroacetic acid was added to the homogenates (1:3). The samples were centrifuged for $10 \mathrm{~min}$ at 12000 $\times g$, supernatants retained, the pellets redissolved in $5-10 \mathrm{~mL}$ $5 \%$ trichloroacetic acid, and recentrifuged $(10 \mathrm{~min}, 12000 \times \mathrm{g})$. The supernatants from these two steps were counted separately in a liquid scintillation spectrometer (Packard Tricarb model 3320) after addition of $10 \mathrm{~mL}$ of Aquasol-2 (New England Nuclear, Boston, MA) to $1 \mathrm{~mL}$ of supernatant. The counting efficiency in the ${ }^{3} \mathrm{H}$ and ${ }^{14} \mathrm{C}$ channels was determined with standard quenching curves. In two experiments, the final pellets were rehomogenized and, after addition of trichloroacetic acid, centrifuged for a third time; this supernatant contained less than $3 \%$ of the counts from the first supernatant. AIB-standard (3.68 $\left.\times 10^{-10} \mathrm{~mol}\right)$ and MG-standard $\left(2.6 \times 10^{-13} \mathrm{~mol}\right)$ corresponded to $51000 \pm 1300 \mathrm{dpm}$ and $30000 \pm 200 \mathrm{dpm}$, respectively, $(n$ $=7)$.

In total, 135 animals with fetuses in both uterine horns went through the ligation operation. In $26 \%$ of these does, fetuses in the ligated horn were dead at the time of catheterization. In another $21 \%$ of the animals, fetuses on the operated side died between catheterization and the day of experimentation. In $10 \%$ of the ligated animals, no growth retardation was observed at autopsy. In the rest of the cases $(43 \%)$, varying degrees of wt reduction were found. However, in a majority of these animals ( $29 \%$ of the initial 135), complications like postoperative deaths of the doe, catheter failure, stressful behavior in the experimental situation, etc., appeared. The rest of the animals (14\%) went through successful experiments.

Results are expressed as means \pm SEM. To evaluate statistical significance of differences between growth-retarded and control groups, $t$ test for paired observations was used.

\section{RESULTS}

General characteristics of the 19 animals are given in Table 1 . In the $\mathrm{d} 50$ and $\mathrm{d} 63$ groups, growth retardation was arbitrarily defined as $>20 \%$ wt reduction compared with the mean FW in the control horn. In cases of more than one control or growthretarded fetus present in the horn, a mean value was calculated for the horn. In one experiment, at d 63 , the nonligated horn contained two small fetuses together with one normal-sized control; these two runts exhibited the same changes in substrate transfer parameters as the small fetuses in the ligated horn and were included in the growth-retarded group. At d 44, data from all fetuses in the ligated horn are presented, because at this gestational age no substantial reduction of FW was recorded. 
Table 1. General characteristics of 19 animals*

\begin{tabular}{lccc}
\hline & $\mathrm{d} 44$ & $\mathrm{~d} 50$ & $\mathrm{~d} 63$ \\
\hline$n$ & 6 & 6 & 7 \\
Maternal wt $(\mathrm{g})$ & $810 \pm 32$ & $908 \pm 54$ & $931 \pm 52$ \\
Blood pressure (mm Hg) & $59.7 \pm 1.4$ & $55.5 \pm 2.2$ & $59.6 \pm 1.8$ \\
Heart rate (bpm) & $286 \pm 10$ & $262 \pm 11$ & $271 \pm 7$ \\
Litter size $(n)$ & $2.83 \pm 0.31$ & $2.50 \pm 0.22$ & $3.00 \pm 0.40$ \\
Total fetal mass (g) & $56.1 \pm 9.0$ & $76.0 \pm 7.4$ & $233 \pm 30$ \\
Total placental blood flow & $14.4 \pm 2.1$ & $14.9 \pm 2.0$ & $29.0 \pm 2.6$ \\
$\quad(\mathrm{~mL} /$ min) & & & \\
\hline
\end{tabular}

$*$ Values are means \pm SEM.

At d 44 , FW was reduced by $16 \%$ and placental wt by $18 \%$ in the ligated horn (Table 2 ). The moderate effect of uterine artery ligation on fetal growth was not due to an unsuccessful reduction of $\mathrm{PBF}$, inasmuch as $\mathrm{FW} / \mathrm{PBF}$ was increased by $112 \%$. At d 50 and 63 of gestation, FW/PBF was increased by 80 and $51 \%$, respectively, whereas fetal and placental wt were reduced in proportion $(\sim 40 \%)$ in the growth-retarded group.

The uptakes of AIB and MG in placentas and fetuses are presented as dpm in Table 3. Feto-placental dpm/PBF represents the feto-placental extraction of the substrate analog from the maternal PBF and fetal $\mathrm{dpm} / \mathrm{g}$ placenta provides an estimate of placental transfer efficiency. Fetal and maternal blood concentrations of substrate analogs were measured in the $\mathrm{d} 44$ and $\mathrm{d} 50$ groups and placental/blood concentration ratios are given in Table 4.

Figures 1 and 2 show substrate uptake in growth-retarded fetuses expressed as percent of controls. The fetal uptake of AIB was unaffected in the ligated group at $\mathrm{d} 44$ (Fig. 1), but was reduced by $33(p<0.05)$ and $18 \%(p<0.05)$ at $\mathrm{d} 50$ and 63 , respectively. A tendency for increased extraction could be demonstrated, but was significantly higher only in late gestation. Placental efficiency to transfer AIB was reduced by $36 \%$ at d 50 $(p<0.05)$ and $22 \%(p<0.01)$ at $\mathrm{d} 63$ of gestation. Placental uptake of AIB per $g$ placenta in the growth retarded groups did not differ from controls (data not shown).

Fetal uptake of MG per $\mathrm{g}$ fetus was slightly reduced $(-6 \%, p$ $<0.05$ ) at d 50 of gestation (Fig. 2) but unaffected at d 44 and d 63. Feto-placental dpm/PBF was increased at all stages of gestation studied, suggesting an increased extraction of $M G$ from the maternal PBF. The wt-specific transfer capacity of the placenta was unchanged throughout gestation (Fig. 2), and no difference in placental dpm/g placenta could be demonstrated (data not shown).

\section{DISCUSSION}

Our study is, to our knowledge, the first to describe substrate transfer characteristics of the growth-retarded hemochorial placenta in the awake, unstressed animal. Another novel aspect of these experiments is that they present placental transfer data from three stages of gestation, thereby demonstrating that pla- cental AIB transfer to growth-retarded fetuses is substantially reduced during a prolonged period of late gestation. This finding adds evidence to the hypothesis that a reduced fetal amino acid availability due to an impaired placental transfer is a contributing factor to the development of growth retardation. We have also demonstrated that placental MG transfer to the growth-retarded fetuses in relation to FW is largely unaffected during the last 3 wk of gestation.

In our study, growth retardation was associated with an increased $\mathrm{FW} / \mathrm{PBF}$ ratio, a characteristic also described for IUGR in humans (9). As a consequence, the growth-retarded fetus is supplied by a lower maternal PBF per unit fetus, and to maintain substrate supply, the feto-placental unit must extract more from the placental circulation. In our study, the increased feto-placental dpm/PBF ratio for MG and, to some extent, for AIB indicate that this is the case. At d 44, only a moderate reduction of fetal and placental wt could be demonstrated despite a substantial increase in FW/PBF. Inasmuch as guinea pig fetuses weigh approximately $4 \mathrm{~g}$ at the time of ligation (10), this suggests that fetal growth is relatively independent of PBF until d 44 of gestation. This finding is consistent with an earlier report from this laboratory (11) in which no correlation could be demonstrated between FW and PBF at d 45 of gestation after unilateral uterine artery ligation 2 wk earlier.

The placental transfer of AIB (fetal dpm/g fetus) was substantially reduced in growth retardation both at d 50 and 63 of gestation (Fig. 1). Our data are in line with the results of Nitzan et al. (7), who studied placental AIB transfer in the anesthetized rat after uterine artery ligation and were able to demonstrate a large reduction in AIB-uptake in IUGR fetuses. In addition, Saintonge and Rosso (8) have shown in the anesthetized guinea pig that fetuses of a lower wt than average due to natural intralitter variations also have a slightly reduced uptake of AIB per $\mathrm{g}$ fetus. AIB is transferred by the sodium-dependent amino acid transporting system that is responsible for the transport of glycine, alanine, and serine. In the study of Cetin et al. (5), in which the amino acid profiles in human umbilical blood were described, serine was one of the six amino acids that had a lower umbilical vein concentration in growth-retarded compared with appropriately grown fetuses.

Reductions in PBF result in a reduced transfer of $\alpha$-amino nitrogen to the fetus $(12,13)$. Other factors that are likely to influence the rate of placental amino acid transfer are the placental membrane area available for exchange and the transfer efficiency of the placental barrier. In human idiopathic IUGR, microvillous surface area in relation to $\mathrm{FW}$ has been shown to be substantially increased (14). Provided that amino acid transfer mainly occurs in the microvillous part of the placental barrier, this will tend to enhance amino acid transfer in IUGR. However, studies of AIB transport in human placental microvilli vesicles have demonstrated that cell membranes from placentas of smallfor-gestational-age infants have a decreased transfer capacity (15). Data concerning microvillous surface area or specific placental amino acid transfer capacity are not currently available for

Table 2. FW, placental $w t, P B F$, and $F W / P B F$ at $d 44,50$, and 63 after unilateral uterine ligation at d 31-38*

\begin{tabular}{|c|c|c|c|c|c|c|}
\hline & \multicolumn{2}{|c|}{$\mathrm{d} 44(n=6)$} & \multicolumn{2}{|c|}{ d $50(n=6)$} & \multicolumn{2}{|c|}{$\mathrm{d} 63(n=7)$} \\
\hline & Control & Ligated & Control & Growth retarded & Control & Growth retarded \\
\hline FW (g) & $21.6 \pm 1.6$ & $18.2 \pm 1.2 \ddagger$ & $40.2 \pm 1.22$ & $22.4 \pm 2.18 \S$ & $99.2 \pm 2.8$ & $60.7 \pm 4.4 \S$ \\
\hline Placental wt (g) & $3.06 \pm 0.27$ & $2.50 \pm 0.19 \dagger$ & $3.95 \pm 0.15$ & $2.29 \pm 0.18 \S$ & $5.14 \pm 0.23$ & $3.23 \pm 0.24 \S$ \\
\hline $\mathrm{PBF}(\mathrm{mL} / \mathrm{min} \times \mathrm{g})$ & $2.52 \pm 0.26$ & $1.40 \pm 0.14 \dagger$ & $2.32 \pm 0.20$ & $1.33 \pm 0.10 \dagger$ & $2.88 \pm 0.10$ & $1.99 \pm 0.16 \S$ \\
\hline $\mathrm{PBF}(\mathrm{mL} / \mathrm{min})$ & $7.90 \pm 1.22$ & $3.58 \pm 0.54 \dagger$ & $9.15 \pm 0.83$ & $3.12 \pm 0.45 \ddagger$ & $14.7 \pm 0.60$ & $6.42 \pm 0.63 \S$ \\
\hline $\mathrm{FW} / \mathrm{PBF}$ & $3.04 \pm 0.44$ & $6.45 \pm 1.0 \dagger$ & $4.22 \pm 0.43$ & $7.58 \pm 0.49 \pm$ & $6.87 \pm 0.41$ & $10.37 \pm 1.52 \ddagger$ \\
\hline
\end{tabular}

* Values are means \pm SEM. The given ratios represent the mean value of ratios in individual experiments. For mathematical reasons, the presented ratio for $\mathrm{FW} / \mathrm{PBF}$, for example, is therefore not identical to the ratio obtained by dividing mean $\mathrm{FW} / \mathrm{mean} \mathrm{PBF}$.

$\dagger p<0.05$, paired $t$ test.

$\ddagger p<0.01$, paired $t$ test.

$\S p<0.001$, paired $t$ test. 


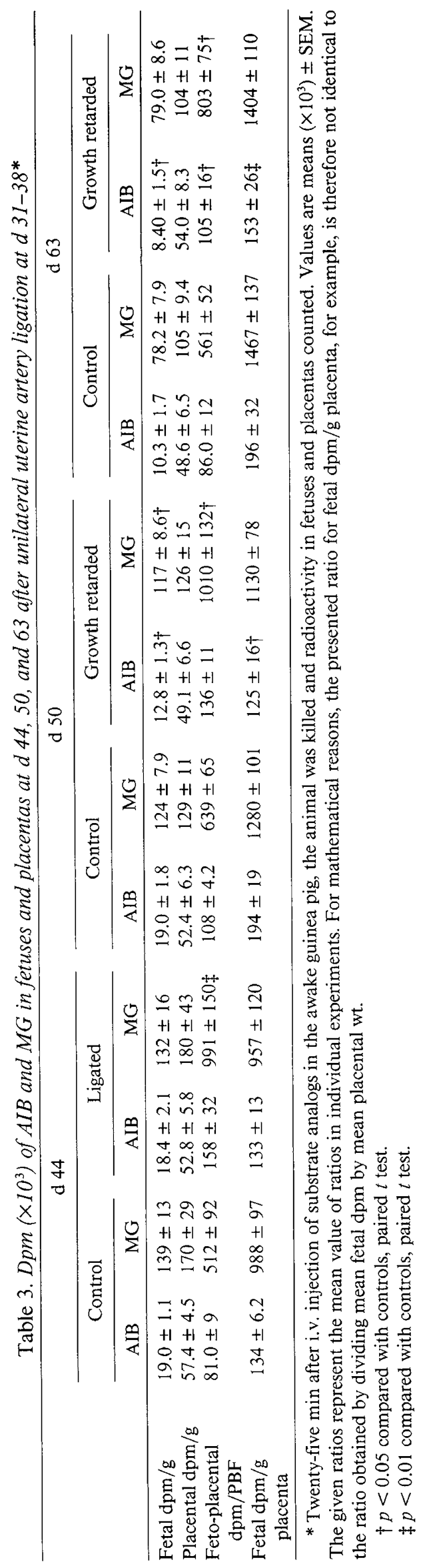

guinea pig IUGR. We suggest that, in addition to the reduced $\mathrm{PBF}$, alterations at the placental barrier level contribute to the reduced $\mathrm{AIB}$ transfer in our study.

Clearance values for AIB transport from mother to fetus have been calculated in the anesthetized guinea pig with intact placenta as well as in the isolated artificially perfused organ (16). These values were in the range of $0.3-0.8 \mathrm{~mL} / \mathrm{min}$. In our study, we used a single injection technique and, inasmuch as maternal blood concentrations of AIB are available only at the end of the experiment, an estimate of a mean maternal concentration will of necessity be only approximate. Nevertheless, the mean blood concentration in the d 50 animals was $6500 \mathrm{dpm} / \mathrm{mL}$. If we assume that the mean maternal blood concentrations of AIB during the whole experimental period was $\sim 10000 \mathrm{dpm} / \mathrm{mL}$, this will correspond to a clearance value of $3 \mathrm{~mL} / \mathrm{min}$, inasmuch as fetal uptake was $30000 \mathrm{dpm} / \mathrm{min}$ (Tables 2 and 3). The same calculation for the growth-retarded group at d 50 of gestation gives a value of $1.2 \mathrm{~mL} / \mathrm{min}$. These values are higher than the results of van Dijk and van Kreel (16), which may illustrate that anesthesia slows active placental transfer processes.

The technique of using substrate analogs to study placental transfer is well suited for comparing the uptake of growthretarded and normal-sized fetuses in the same litter. It is likely to be less accurate when comparisons between the different gestational age groups are concerned. Nevertheless, the reduction in wt-specific MG-uptake of control fetuses at d 63 as compared with that at $\mathrm{d} 44$ is compatible with the findings of Peeters et al. (17). They could demonstrate a $21 \%$ lower wt-specific uterine glucose uptake in late gestation compared with midgestation in the awake guinea pig. Similarly, fetal AIB uptake was reduced in our d 63 group as compared with d 44 . Because this reduction occurs during a period when fetal protein accretion increases (17), it may indicate that a substantial part of the amino acid uptake of the fetal guinea pig in midgestation serves catabolic purposes. It has been demonstrated that umbilical uptake of branched amino acids in the fetal sheep exceeds their rate of tissue accretion by 3-4 times (18). To our knowledge, no experimental data describing the fate of amino acids taken up by the guinea pig fetus are available. Thus, it is difficult to predict whether the observed reduction in AIB transfer to growth-retarded fetuses will affect catabolic, anabolic, or both pathways. It has been estimated that the caloric equivalent of fetal glucose uptake in the late gestational guinea pig represents $39 \%$ of total caloric demand, which completely corresponds to the need for nongrowth purposes (17). This may indicate that amino acid uptake in late gestation is mainly directed toward accretion of new fetal tissues. Furthermore, in growth-retarded fetuses, the drastically reduced activity of aminotransferases in the liver (19) will tend to deviate amino acids away from gluconeogenetic pathways. Consequently, we speculate that the reduced amino acid availability in growth-retarded fetuses of our study, as suggested by the impaired placental AIB transfer, will result in a reduced protein accretion.

The placental/maternal blood concentration ratios for $\mathrm{MG}$ were not clearly lower than 1.0 in our study, which may indicate that the carrier-mediated transfer of MG (20) has become saturated before the termination of the experiment. However, the MG uptake of the growth-retarded fetuses compared with that of controls was very consistent, with low variability despite varying placental/maternal blood concentration ratios. In the $\mathrm{d}$ 50 group, a couple of individual growth-retarded fetuses had ratios well below 1 ; despite that, they exhibited a 5-6\% reduction in wt-specific MG uptake, which is identical to that of the group as a whole. The same was true for the $\mathrm{d} 44$ group, in which two fetuses in the ligated horn with ratios around 0.80 did not deviate from the group mean. Thus, inasmuch as the MG uptake results were clearly independent of placental/maternal blood concentration ratios, we conclude that the fact that the mean ratios were close to 1 will not influence the comparison between growthretarded and normal-sized fetuses. 
Table 4. Concentration ratios (placental $\mathrm{dpm} / \mathrm{g}$ placenta divided by blood $\mathrm{dpm} / \mathrm{mL}$ ) for substrate analogs*

\begin{tabular}{|c|c|c|c|c|c|c|c|c|}
\hline & \multicolumn{4}{|c|}{${ }^{14} \mathrm{C}$-aminoisobutyric acid } & \multicolumn{4}{|c|}{${ }^{3} \mathrm{H}$-methylglucose } \\
\hline & \multicolumn{2}{|c|}{$\mathrm{d} 44(n=5)$} & \multicolumn{2}{|c|}{ d $50(n=6)$} & \multicolumn{2}{|c|}{$\mathrm{d} 44(n=5)$} & \multicolumn{2}{|c|}{ d $50(n=6)$} \\
\hline & Control & Ligated & Control & Growth retarded & Control & Ligated & Control & Growth retarded \\
\hline $\mathrm{P} \mathrm{dpm} / \mathrm{Mb} \mathrm{dpm}$ & $7.99 \pm 0.85$ & $7.26 \pm 0.81$ & $7.98 \pm 0.72$ & $7.43 \pm 0.79$ & $1.03 \pm 0.06$ & $0.99 \pm 0.03$ & $1.04 \pm 0.07$ & $1.00 \pm 0.10$ \\
\hline $\mathrm{Pdpm} / \mathrm{Fb} \mathrm{dpm}$ & $6.80 \pm 1.06$ & $5.98 \pm 0.87$ & $5.93 \pm 0.80$ & $6.77 \pm 1.30$ & $1.15 \pm 0.09$ & $1.06 \pm 0.04$ & $1.05 \pm 0.06$ & $1.13 \pm 0.14$ \\
\hline
\end{tabular}

* Means \pm SEM. P, placenta; Mb, maternal blood; Fb, fetal blood.

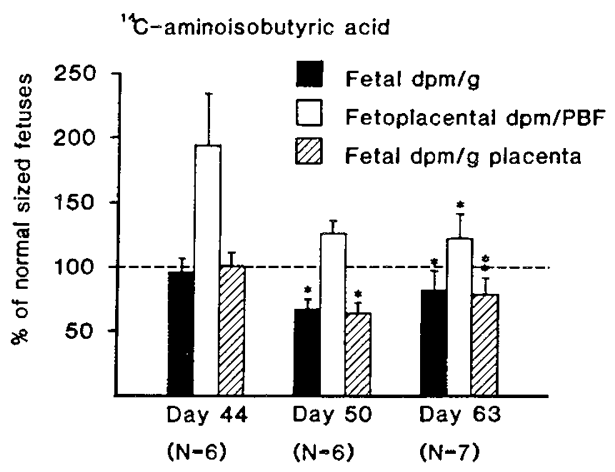

Fig. 1. Uptake of ${ }^{14} \mathrm{C}$-AIB in growth-retarded fetuses and placentas expressed as $\%$ of uptake in paired controls. Values are means \pm SEM. ${ }^{*} p<0.05,{ }^{* *} p<0.01$.

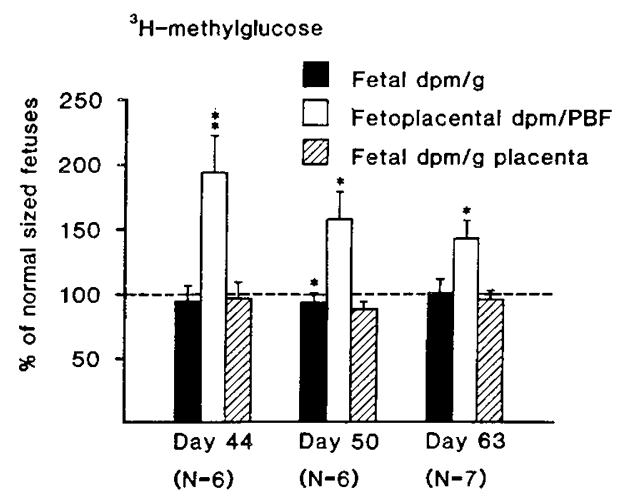

Fig. 2. Uptake of ${ }^{3} \mathrm{H}-\mathrm{MG}$ in growth-retarded fetuses and placentas expressed as \% of uptake in paired controls. Values are means \pm SEM. ${ }^{*} p<0.05,{ }^{* *} p<0.01$.

The wt-specific fetal uptake of MG was slightly but significantly reduced in the growth-retarded group at $\mathrm{d} 50$ of gestation. This is in agreement with a study carried out in the anesthetized rat (7) in which placental transfer of $\mathrm{MG}$ was reduced by $17 \%$ in a group of growth-retarded fetuses at d 20 of gestation after uterine artery ligation at $\mathrm{d} 18$. In our study, no reduction in placental transfer of $\mathrm{MG}$ could be demonstrated at d 63 of gestation due to a maintained placental efficiency to transport MG (expressed as fetal dpm/g placenta) together with an increased uteroplacental extraction to compensate for the increase in FW/PBF. Transport studies with light scattering techniques on guinea pig placentas at d 63 of gestation show that microvillous membranes from growth-retarded placentas transport glucose as efficiently as membranes from normal-sized placentas (Illsley N, Jansson T, unpublished data), which is compatible with our observations. In addition, an increased materno-fetal concentration gradient, due to fetal hypoglycemia in IUGR (2), will stimulate the transplacental glucose transfer. Thus, an unchanged specific efficiency of the placental membrane to transfer glucose, a steeper concentration gradient, and possibly an increased microvillous-surface area in guinea pig IUGR seem to counteract the effect of reduced PBF on glucose transfer.

In the fetal sheep, experimental growth retardation seems to be associated with an increased placental efficiency to transport glucose (6). Furthermore, a redistribution of glucose consumption from the placenta to the fetus is observed when placental growth is restricted (1). Our results do not support a reduced glucose uptake in the growth-retarded placenta of the guinea pig, inasmuch as no difference in placental dpm/g placenta could be demonstrated between groups. These discrepancies between the two animal models may be due to fundamental differences in the way of inducing growth retardation. In the sheep, uterine caruncles are excised before conception, restricting the number of cotyledons that develop during early placental growth. Consequently, the restriction is present during the entire pregnancy, unlike with uterine artery ligation in rodents, where pregnancy continues undisturbed until midgestation, when PBF is reduced. In the sheep model, the fetal/placental wt ratio increases (1), whereas in the guinea pig model, as in the human (9), fetal and placental wt are reduced in proportion. Moreover, the sheep placental type is epiteliochorial and may have other transport characteristics than the hemochorial placentas of guinea pigs and humans.

The unaffected placental transfer of MG in late gestation in our study indicates that the fetal hypoglycemia associated with IUGR in the guinea pig (2) is caused, at least in part, by factors other than reduced transplacental supply of glucose. The reduced fetal AIB uptake demonstrated in our study may restrict the availability of gluconeogenetic substrates and contribute to reduced plasma levels of glucose. In addition, both animal experimental (19) and human data (21) suggest that gluconeogenesis is impaired in fetal growth retardation, partly due to a delayed appearance of gluconeogenetic enzymes in the liver. An increased fetal consumption of glucose could also explain lower plasma glucose levels despite a maintained placental glucose transfer. However, no experimental support for this hypothesis is at hand, inasmuch as the growth-retarded fetal sheep has an unchanged glucose consumption (1).

Our results relating to glucose transfer in growth retardation in the guinea pig should not freely be extrapolated to the human. In a recent study by Economides and Nicolaides (3), umbilical artery and vein glucose concentrations were measured in smallfor-gestational-age fetuses by means of cordocentesis. They demonstrated a slightly reduced umbilical vein-artery concentration difference of glucose in growth-retarded compared with normalsized fetuses. If this information is combined with data of umbilical volume blood flow obtained from Doppler studies of growth-retarded fetuses (22), suggesting a reduced umbilical flow $/ \mathrm{kg}$ fetus, a reduced fetal uptake of glucose per $\mathrm{kg}$ fetus in human IUGR seems possible.

In conclusion, our results demonstrate that experimental growth retardation in the guinea pig is associated with a substantial reduction of FW-specific placental transfer of AIB, indicating that the growth-retarded fetus has an impaired supply of amino acids during intrauterine life. This reduction is suggested to be partly due to alterations at the placental barrier level and will contribute to the development of growth retardation independent of the PBF decrease per se. Placental transfer of MG per g fetus was only moderately reduced at d 50 of gestation, but otherwise maintained. Fetal hypoglycemia in guinea pig IUGR is therefore likely to be due, at least in part, to factors other than impaired placental glucose transfer. 


\section{REFERENCES}

1. Owens JA, Falconer J, Robinson JS 1987 Effect of restriction of placental growth on fetal and utero-placental metabolism. J Dev Physiol 9:225-238

2. Jones CT, Lafeber HN, Roebuck MM 1984 Studies on the growth of the fetal guinea pig. Changes in plasma hormone concentration during normal and abnormal growth. J Dev Physiol 6:461-472

3. Economides DL, Nicolaides KH 1989 Blood glucose and oxygen tension levels in small-for-gestational-age fetuses. Am J Obstet Gyncrol 160:385-389

4. Prenton MA, Young M 1969 Umbilical vein-artery and uterme arterio-venous plasma amino acid differences (in the human subject). J Obstet Gynaecol Br Commonw 76:404-411

5. Cetin I, Marconi AM, Bozzetti P, Sereni LP, Corbetta C, Pardi G, Battaglia FC 1988 Umbilical amino acid concentrations in appropriate and small for gestational age infants: a biochemical difference present in utero. Am J Obstet Gynecol 158:120-126

6. Owens JA, Falconer J, Robinson JS 1987 Restriction of placental size in sheep enhances efficiency of placental transfer of antipyrine, 3-O-methyl-D-glucose but not of urea. J Dev Physiol 9:457-464

7. Nitzan M, Orloff S, Schulman JD 1979 Placental transfer of analogs of glucose and amino acids in experimental intrauterine growth retardation. Pediatr Res 13:100-103

8. Saintonge J, Rosso P 1981 Placental blood flow and transfer of nutrient analogs in large, average and small guinea pig littermates. Pediatr Res 15:152-156

9. Nylund L, Lunell N-O, Lewander R, Sarby B 1983 Uteroplacental blood flow index in intrauterine growth retardation of fetal and maternal origin. $\mathrm{Br} \mathrm{J}$ Obstet Gynaecol 90:16-20

10. Draper RL 1920 The prenatal growth of the guinea pig. Anat Rec 18:369-392

11. Jansson T, Thordstein M, Kjellmer I 1986 Placental blood flow and fetal weight following uterine artery ligation. Temporal aspects of intrauterine growth retardation in the guinea pig. Biol Neonate 49:172-180

12. Krauer F, Joyce J, Young M 1973 The influence of high maternal plasma glucose levels, and maternal blood flow on the placental transfer of glucose in the guinea-pig. Diabetologia 9:453-456

13. Joyce J, Young M 1974 A comparison of the effect of a reduction in maternal blood flow on the placental transfer of glucose and amino nitrogen from mother to foetus. J Physiol 239:5P(abstr)

14. Teasdale $F$, Jean-Jacques G 1988 Intrauterine growth retardation: morphometry of the microvillous membrane of the human placenta. Placenta 9:4755

15. Dicke JM, Henderson GI 1988 Placental amino acid uptake in normal and complicated pregnancies. Am J Med Sci 295:223-227

16. van Dijk JP, van Kreel BK 1978 Transport and accumulation of $\alpha$-aminoisobutyric acid (A.I.B.) in the guinea pig placenta. Pflugers Arch 377:217-224

17. Peeters LL, Verkeste CM, Wallenburg HCS, Saxena PR, van Kreel BK 1989 Role of maternal glucose as a metabolic substrate for the guinea pig conceptus. Pediatr Res 25:641-644

18. Battaglia FC 1979 Umbilical uptake of substrates and their role in fetal metabolism. In: Visser HKA (ed) Nutrition and Metabolism of the Fetus and Infant. Martinus Nijhoff, The Hague, pp 83-91

19. Lafeber HN 1981 Experimental intra-uterine growth retardation in the guinea pig. Erasmus Universiteit, Rotterdam. Thesis.

20. Schröder H, Leichtweiss H-P, Madee W 1975 The transport of D-glucose, Lglucose and D-mannose across the isolated guinea pig placenta. Pflugers Arch $356: 267-275$

21. Haymond MW, Karl IE, Pagliara AS 1974 Increased gluconeogenetic substrates in the small-for-gestational age infant. N Engl J Med 291:322-328

22. Laurin J, Lingman G, Marsal K, Persson P-H 1987 Fetal blood flow in pregnancies complicated by intrauterine growth retardation. Obstet Gynecol 69:895-902 